\title{
ESCRAVOS NOS TRIBUNAIS: ESTRATÉGIAS E EXPECTATIVAS NAS AÇÕES DE LIBERDADE DO SÉCULO XIX*
}

\author{
Letícia Graziele de Freitas Lemes**
}

\begin{abstract}
Resumo: Este artigo aponta algumas discussões a partir da análise de ações cíveis de liberdade que tiveram lugar na Corte do Rio de Janeiro, no século XIX. Discutimos as estratégias dos escravos diante da possibilidade de ter sua liberdade disputada judicialmente, buscando entender como os cativos lidavam com o direito e as leis, as condições que os motivavam ou possibilitavam sua ida ao tribunal, e como obtinham aliados nessa luta contra seus supostos senhores.
\end{abstract}

Palavras-chave: Escravidão. Escravização ilegal. Ações de liberdade.

Slaves in the courts: strategies and expectations in freedom lawsuits in the nineteenth century

Abstract: This paper shows some discussions from the analysis of civil actions for freedom that took place at Rio de Janeiro Court in the nineteenth century. It discusses the strategies of slaves before the possibility of having their freedom disputed in court. It seeks to understand how captives dealt with law and rights, the conditions which motivated and allowed slaves to go to court and how they managed to obtain allies in this struggle against their alleged masters.

Keywords: Slavery. Illegal enslavement. Freedom lawsuits.

\footnotetext{
* O presente texto é fruto de uma pesquisa realizada durante curso de graduação em História na Universidade Estadual de Campinas, com auxílio concedido pelo $\mathrm{CNPq}$ no Programa Institucional de Bolsas de Iniciação Científica entre julho/2010 e julho/2011, sob orientação do Prof. Dr. Sidney Chalhoub.

** Instituto de Filosofia e Ciências Humanas, Universidade Estadual de Campinas - Unicamp, Campinas-SP, Brasil (legrafreitas@gmail.com).

Recebido em: 30/11/2014 - Aceito em: 11/05/2015.
} 
$|166|$

Escravos nos tribunais...

Esclavos en los tribunales: estrategias y expectativas en las acciones de libertad del siglo XIX

Resumen: Este artículo señala algunas discusiones a partir del análisis de acciones civiles de libertad que tuvieron lugar en la Corte de Rio de Janeiro, en el siglo XIX. Discutimos las estrategias de los esclavos frente a la posibilidad de tener su libertad judicialmente disputada, tratando de entender cómo los cautivos lidiaban con el derecho y las leyes, las condiciones que les motivaban o posibilitaban ir a la corte, y cómo obtenían aliados en esta lucha contra sus supuestos señores.

Palabras clave: Esclavitud. Esclavitud ilegal. Acciones de libertad.

\section{Introdução}

Ao longo do século XIX, se multiplicaram nos tribunais do Império do Brasil os processos cíveis iniciados por cativos para aquisição da liberdade. Tais processos são chamados de ações de liberdade e desafiaram abertamente o poder senhorial de arbitrar sobre a vida e a condição de seus cativos. A análise das ações de liberdade pelos historiadores nas últimas décadas tem colaborado para compreender as lutas e estratégias cativas, assim como o confronto de valores e interpretações do direito que se davam entre senhor e escravo na arena jurídica.

Análises como as de Azevedo (1999; 2003), Mendonça (2008), Chalhoub (1990), Pena (2001) e Grinberg (1994) mostraram que, apesar de fazer parte do aparato de um Estado escravista, os tribunais e as leis do Império brasileiro foram espaços imprevisíveis de confronto de classes, em que a possibilidade de alforria se dava de maneira real. Esses estudos apontaram também para a relevância das leis emancipacionistas ${ }^{1}$ para o declínio do sistema escravista e o reconhecimento legal de direitos reivindicados pela população cativa, assim como seu valor dentro das discussões parlamentares e judiciais.

\footnotetext{
${ }^{1}$ Tais como a lei 2.040, que ficou conhecida como "Lei do Ventre Livre", promulgada em 1871 e a lei 3.270, promulgada em 1885, que ficou conhecida como "Lei dos Sexagenários".
} 
A questão que ainda se impõe diante dessas importantes análises é entender com maior exatidão como os escravos chegavam aos tribunais. Esse tema se articula com as recentes pesquisas historiográficas que discutem as práticas de escravização ilegal, bastante enraizadas na sociedade oitocentista, e as estratégias cativas para combatê-las e deslegitimá-las. O presente texto, por sua vez, é parte de um estudo que caminha nesse sentido, isto é, a busca por entrever as estratégias e dispositivos que os cativos podiam acionar, e de fato acionavam, para que a reivindicação da liberdade na justiça fosse iniciada. Esperamos assim, compreender a forma como os escravos lidavam com as leis e o espaço jurídico, e com as possibilidades de alforria delineadas pelo crescente questionamento da instituição escravista na época² ${ }^{2}$.

Os documentos examinados para o estudo proposto foram as apelações cíveis julgadas pelo Tribunal da Relação do Rio de Janeiro $^{3}$, iniciadas entre 1812 e 1878 na Corte do Rio de Janeiro ${ }^{4}$.

Centro do governo imperial desde 1808, a Corte se configurou como importante local de debate e decisões parlamentares, assim como espaço de mobilidade dos milhares de escravos que compunham sua população. Assim, a cidade foi escolhida de forma especial para o estudo dessas ações por abrigar o tribunal da Relação do Rio de Janeiro e por ter sido o lugar onde mais se abriram ações de liberdade no século XIX, com uma porcentagem alta de sentenças favoráveis aos cativos.

As apelações cíveis são documentos extensos, que possuem uma petição inicial em nome do escravo litigante, mas assinada

\footnotetext{
${ }^{2}$ Conclusões e discussões mais detalhadas desse estudo podem ser vistas em FREITAS. L. G. B. Escravos nos tribunais: o recurso à legislação emancipacionista em ações de liberdade do século XIX. Monografia, Unicamp, Campinas, 2012.

${ }^{3}$ O Tribunal da Relação do Rio de Janeiro era responsável por julgar em segunda instância processos iniciados no Sudeste no Império.

${ }^{4}$ Documentação constante do fundo "Relação do Rio de Janeiro", armazenada no Arquivo Edgard Leuenroth (AEL - IFCH - UNICAMP).
} 
| 168 |

Escravos nos tribunais...

por um homem livre ${ }^{5}$; um auto de depósito para a liberdade ${ }^{6}$; depoimentos de testemunhas; autos de contrariedade que trazem a defesa do proprietário do escravo; o libelo cível, em que o argumento para a liberdade é desenvolvido pelo curador do cativo e, por fim, a decisão judicial - sentença (na primeira instância) ou acórdão (quando advinda no Tribunal da Relação). A análise se estendeu especialmente sobre a leitura desses "capítulos" dos processos, em busca de pistas sobre como o cativo obteve o conhecimento da ilegalidade de sua condição, a sua relação com as pessoas livres ou libertas que estavam ao seu redor, envolvidas de maneira direta ou não no processo, os conflitos com o senhor durante o litígio, se o escravo tentou outras formas de obter a alforria e como ele efetivamente chegou à justiça.

Neste texto, vamos explorar um dos processos encontrados nos arquivos, de modo a apresentar algumas das reflexões da pesquisa. Trata-se da ação de liberdade iniciada pela parda Vitória, em 1857, contra seu senhor Manoel Simões da Silva7.

\footnotetext{
${ }^{5} \mathrm{O}$ escravo não tinha sua pessoa reconhecida juridicamente e por isso não podia ir a juízo sem um homem livre que assinasse seus requerimentos e um representante legal, isto é, o curador.

${ }^{6}$ Para evitar represálias senhoriais durante o processo, o escravo litigante era depositado em poder de uma pessoa livre, que se responsabilizasse por ele e o levasse ao tribunal quando solicitado. Quando nenhuma pessoa livre se apresentava diretamente para exercer os papéis de curador, procurador ou depositário do cativo litigante, eles eram nomeados pelo juiz municipal entre os que atuavam habitualmente nos foros.

${ }^{7}$ Apelação Cível sobre liberdade de escravo. Apelante: Vitória, escrava de Manoel Simões da Silva. Apelado: Manoel Simões da Silva. Rio de Janeiro, 17/03/1858 a 02/07/1859. (Referência no AEL: 84.0.ACI.79, localização: RRJ mr 026).
} 


\section{Vitória e o princípio da liberdade}

A história contada na Ação de Liberdade da parda Vitória começa 17 anos antes, quando ela era escrava de Francisco Eduardo Alves Viana, morador da Corte. Em abril de 1840, Francisco Viana embarcou com sua esposa e mais duas escravas no Porto do Rio de Janeiro em direção a Bordeaux, na França. O que Vitória alegou em juízo foi que ela era uma das escravas levadas por Viana à França. Soube-se, pela cópia da legitimação para os passaportes solicitados pelo senhor na época, que ele levara consigo uma preta, de nome Joaquina, e uma parda, de nome Benvinda. Dessa forma, não havia prova documental da participação de Vitória na viagem. Ela alegou, no entanto, que teria viajado usando o passaporte da parda Benvinda, já que a ideia inicial de Francisco Viana teria sido levar esta à França, e só depois ele teria resolvido levar Vitória.

A viagem à França foi usada por Vitória para justificar seu direito à liberdade baseando-se na lógica do chamado "princípio da liberdade",

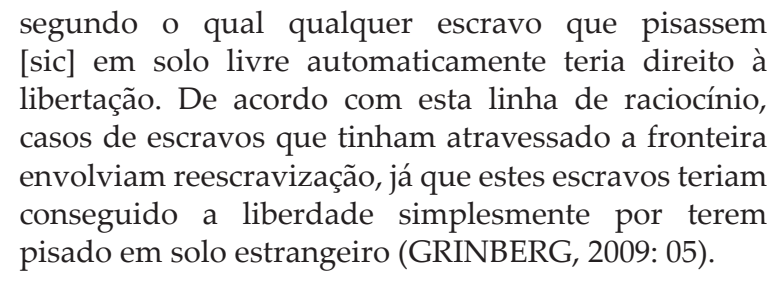

A forma como esse argumento foi recebido em juízo é algo intrigante. $\mathrm{O}$ "princípio da liberdade" não estava escrito em nenhuma disposição legal, no entanto, era aceito como consenso jurídico pelo Direito Internacional e, de fato, não foi em nenhum momento questionado pelos defensores do senhor ou pelos magistrados que julgaram a ação cível de Vitória em primeira e segunda instâncias. A única dúvida que impedia a libertação da parda era se a própria Vitória teria estado na Europa, como alegava. 
| 170 |

Escravos nos tribunais...

Em contrapartida, encontramos processos em que as leis e regulamentos citados, apesar de estar na "letra da lei", foram arduamente questionados pelos advogados senhoriais. Como exemplo, existem diversas ações cíveis iniciadas na década de 1860 reivindicando a liberdade com base na primeira lei de extinção do tráfico transatlântico de escravos, de 7 de novembro de 1831. Apesar de escrita em lei, sua análise em juízo foi bastante complexa, e sua aplicabilidade nem sempre aceita, como mostram estudos de Mamigonian e Grinberg (2007).

Isso mostra que a articulação em torno dessas leis não estava regida por um consenso geral e imparcial, mas sim precedida por análises políticas e ideológicas, ora a favor da liberdade, ora a favor da escravidão. De modo semelhante, as muitas estratégias de senhores e escravos em torno da escravização ilegal foram articuladas nos foros oitocentistas com base em argumentações dispostas em lei ou não.

Os escravos que atuaram nesses foros buscaram forçar ao máximo as linhas que cercavam a possibilidade de liberdade. Basearam-seem histórias e razões múltiplase cheias de sinuosidades que tentaram interpretar e manipular da melhor forma que poderiam. Em alguns momentos encontraram disposições legais que sustentavam a validade de suas reivindicações; em outros, buscaram essa sustentação em ideias consensuais a respeito da relação entre senhor e escravo; em outros ainda, encontraram em advogados abolicionistas aliados decisivos para tornar justificável a ilegitimidade de seu cativeiro nos foros. Nesse sentido, a decisão de entrar na justiça para reclamar a liberdade estava precedida de uma série de interpretações: de documentos, de condições favoráveis, de argumentos que poderiam ser aceitos, de aliados possíveis.

Essa decisão devia contar também com uma análise dos riscos envolvidos em formar um litígio contra o próprio senhor. Como expôs Azevedo (1999: 220), havia um grande perigo para o escravo que demandasse sua liberdade na justiça, uma vez que poderia sofrer duras represálias do senhor. Isso aparece de maneira 
singular no caso de Vitória. Ela só iniciou sua ação de liberdade 14 anos após seu retorno ao Brasil e a consequente reescravização ilegal.

Ela teria viajado com Francisco Eduardo Alves Viana em 1840, e retornado ao Brasil, na Província de Pernambuco, em 1843. Em 1845 ela foi vendida à Corte, e viveu os 11 anos seguintes em poder do Dr. Paula Menezes. Só em 1857, depois de comprada pelo negociante Manoel Simões, Vitória finalmente foi à justiça.

O senhor Manoel Simões ficou deveras irritado pela ação de liberdade ter se iniciado logo após ele ter comprado a escrava. Seu procurador, o advogado Pedro Veloso Rebelo, afirmou que:

é inverossímil senão quase inconcebível, que tendo Victória estado em França e tendo passado por três [ou] quatro vendas, só no fim de dezesseis anos se lembrasse de sua viagem, e se considerasse livre. ${ }^{8}$

A isso, Vitória respondeu que:

não se apresentou à Polícia durante os onze anos que esteve em poder do Doutor Paula Meneses a fim de reclamar pela sua liberdade, porque sempre que saía era acompanhada. ${ }^{9}$

Ao ser comprada pelo réu, Vitória fugiu e se dirigiu à Polícia. Isso nos mostra que o processo de transição de senhor facilitou a ação da escrava em favor de sua liberdade. De acordo com Vitória, sob o poder do Dr. Paula Meneses não lhe era facultada qualquer possibilidade de apresentar-se à polícia, já que era sempre acompanhada quando saía à rua, e essa possibilidade só apareceu quando sob o domínio do negociante Simões.

Essa distância temporal entre o momento em que o indivíduo teria sido escravizado ilegalmente e o início da ação judicial em

8 Ap. c. sobre lib. de esc. Apelante: Vitória. Rio de Janeiro, 17/03/1858 a 02/07/1859. (AEL: 84.0.ACI.79, RRJ mr 026), f. 11v.

${ }^{9}$ Depoimento em audiência pública da parda Vitória. Idem, f. 36-7v. 
que sua liberdade foi disputada causou algum estranhamento na leitura de vários processos de liberdade: em um montante de 39 ações analisadas, verificamos pelo menos cinco que foram iniciadas por volta de dois anos após a escravização ilegal ou o direito que teria conferido liberdade ao escravo litigante. Esse parece um número razoável, e um lapso de tempo também razoável. Por outro lado, encontramos quatro processos iniciados após 5 a 10 anos de cativeiro ilegal, e três casos de pessoas que nasceram livres, mas foram batizados ilegalmente como escravos e só buscaram a justiça para reclamar sua liberdade 20 anos depois.

Entender o porquê desses enormes intervalos de tempo foi uma das questões que impulsionou este estudo. Como o caso de Vitória permite apreender, muitas vezes o escravo encontrava sérias dificuldades para dar início ao enfrentamento do poder senhorial na justiça. Para iniciar uma ação de liberdade, o cativo precisaria conhecer e ter alguma relação de confiança com um homem livre, para que ele assinasse seu requerimento para liberdade. Outra opção seria fugir e se dirigir à Delegacia de Polícia ou à Santa Casa de Misericórdia, buscando nas próprias autoridades legais alguma proteção à sua reivindicação de liberdade. Ambas as atitudes só poderiam ser tomadas após uma séria avaliação dos riscos envolvidos e das possibilidades de sucesso na aquisição da alforria.

Desse modo, é importante abordarmos esse questionamento também por outro ângulo. Isto é, além de questionar por que os cativos esperaram tanto tempo para recorrer à justiça, é necessário entender o que os encorajou ou possibilitou essa procura em determinada conjuntura histórica ou em certo momento de sua trajetória pessoal.

Ponderamos a princípio que o início de uma ação judicial para a liberdade se configurava como uma situação limite, em que outras alternativas tinham se mostrado infrutíferas - como a negociação com o senhor, ou a fuga, por exemplo -, e também como um cálculo entre os riscos daí advindos e as possibilidades de sucesso. 


\section{Aliados pela liberdade}

Além de esperar pela oportunidade certa, a presença de um aliado na luta judicial e também fora dela pode ter sido um fator importante para encorajar e sustentar a luta escrava contra o cativeiro nos tribunais do século XIX. Homens livres, abolicionistas, poderiam auxiliar os escravos de diversas formas no que concerne à luta pela liberdade: assinando seus requerimentos de liberdade, representando-o em juízo como curador, ou defendendo-o como procurador, atuando como depositário, ou como testemunha ${ }^{10}$ no processo.

Outros importantes aliados eram familiares e parceiros escravos, que ajudavam o cativo a juntar seu pecúlio para a compra da alforria, o auxiliavam em fugas para se apresentar à polícia ou em outras estratégias para a liberdade, além de terem importante papel motivador.

Entretanto, também nos deparamos com casos de escravos que aparentavam estar sozinhos em juízo. Foi o que se deu com a parda Vitória. Em novembro de 1857, ela fugiu do poder do senhor Manoel Simões e se dirigiu à Delegacia de Polícia, se declarando livre e sendo posta na Casa de Detenção. Ela não apresentou um requerimento de liberdade assinado por um homem livre, teve seu curador nomeado pelo juiz municipal e permaneceu na Casa de Detenção durante todo o processo, ou seja, não teve um depositário nomeado. Esses fatos talvez evidenciem a ausência de aliados envolvidos de modo direto no processo, uma vez que nenhum homem livre se apresentou para ser seu depositário ou curador.

Por outro lado, a existência de alguma parceria não ligada de maneira direta à disputa judicial não pode ser descartada, uma vez que várias testemunhas disseram conhecer Vitória há muito tempo, o que sugere que ela tinha relações de longa data no local onde residia. Além disso, uma testemunha depôs que a parda teria tentado trocar de senhor antes de recorrer à justiça, pedindo

${ }^{10}$ Apenas pessoas livres podiam atuar como testemunhas nos processos judiciais nessa época. 
que a mãe da testemunha a comprasse, o que mostra que havia, no mínimo, uma relação de confiança entre a escrava e a mãe da testemunha.

No entanto, sua estratégia para trocar de senhor não funcionou, uma vez que a mãe dessa testemunha teria se negado a comprar Vitória por saber que ela era livre por ter viajado à França. Além dela, outras testemunhas confirmaram a história da viagem de Vitória à Europa. Se a história era verídica ou não, nunca saberemos com certeza. Mas importa observar que as testemunhas só poderiam saber de tal acontecimento a partir de informações fornecidas pela própria Vitória, uma vez que ela fora vendida para a Corte após passar três anos em Pernambuco após o retorno da França. Destarte, é pouco provável que alguma das testemunhas tenha presenciado o embarque da parda, ou tivesse alguma relação com ela ou a família de seu senhor nessa época.

Em que medida Vitória espalhou essa história e convenceu as pessoas de sua veracidade somente podemos supor. Mas sugerimos que aqueles que foram a juízo confirmar essa história tinham no mínimo uma relação de solidariedade com a parda, ajudando-a a sustentar sua argumentação no foro.

Desta feita, é preciso olhar com cuidado para as relações verticais e horizontais que os escravos utilizavam em seus embates pela liberdade. Mesmo que não tivessem algum amparo judicial por meio de um curador, procurador ou depositário aliado, homens e mulheres escravizados construíram redes de relações que, mesmo fora dos tribunais, davam sustentação à sua luta pela alforria.

A relevância dos aliados nas batalhas judiciais pela alforria não deve, todavia, nos deixar levar pela ideia de que essa luta era travada por outrem, por protetores que lhes auxiliavam a adquirir a liberdade enquanto os próprios cativos aguardavam o resultado final.

Esse modelo de interpretação foi repetido por muitos escravocratas, que viam grande perigo em admitir que o escravo fosse capaz de lutar ele mesmo por sua alforria. Escravidão e emancipação deviam ser um negócio tratado por homens livres 
e proprietários, como ficou evidente nos discursos de muitos senhores que figuraram como réus nos processos que analisamos. Admitir que fossem seus próprios escravos a tomar a decisão de ir a juízo e pretender sua liberdade contra eles era mais difícil do que relegar essa iniciativa a algum benfeitor. A defesa do senhor Manoel Simões assim alegou a respeito de Vitória: "Provará que a autora foi instigada a produzir essa história por pessoa que a quer forrar porém [sic] que não acordou no preço pedido pelo Réu."11 Simões talvez estivesse se referindo à tentativa de Vitória de ser comprada pela mãe da testemunha citada anteriormente, o que, como vimos, não funcionou devido ao fato de essa senhora estar convencida da ilegalidade do cativeiro da parda.

Vale observar que as práticas de [re] escravização ilegal foram perdendo a legitimidade ao longo do período oitocentista, em especial a partir da segunda metade do século, com uma intensa discussão jurídica entre juízes e advogados da Corte sobre as ações de revogações de alforria. Esse debate, todavia, não se limitou aos homens letrados, mas foi compartilhado nas ruas e senzalas, por libertos e escravos.

Sem negar o mérito dos advogados abolicionistas no processo que garantiu a liberdade de muitos cativos frente à escravização ilegal, devemos observar que os escravizados encontraram suas próprias formas de provocar e formular essas alianças e redes de solidariedade e de aproveitar ao máximo as contribuições que pudessem ter em seu embate contra o cativeiro. À semelhança do litígio da parda Vitória, que tentara trocar de senhor antes de levar a causa ao tribunal, outros processos mostram as tentativas de aquisição de liberdade que antecederam a entrada na justiça e se basearam na articulação de relações pessoais.

Todos esses elementos evidenciam as dificuldades com as quais os cativos teriam que lidar para dar início a uma luta judicial contra seus senhores, com todos os riscos que essa atitude

${ }^{11}$ Ap. c. sobre lib. de esc. Apelante: Vitória. Rio de Janeiro, 17/03/1858 a 02/07/1859. (AEL: 84.0.ACI.79, RRJ mr 026), f. 11v. Cabe ressalvar que Vitória negou a existência de tal pessoa. 
$|176|$

Escravos nos tribunais...

poderia apresentar. Desse modo, é possível compreender o porquê demoravam tanto tempo para levar sua causa de liberdade à justiça.

\section{Os escravos vão aos tribunais}

$\mathrm{Na}$ tentativa de compreender a dificuldade dos cativos de chegar aos tribunais, é plausível pensar que muitos escravos sequer sabiam que poderiam reivindicar tais direitos. Afinal, como e o quanto os escravos entendiam das disposições legais ou documentos que pudessem ser utilizados nos tribunais a favor de sua liberdade é ainda uma importante questão para a historiografia.

Contudo, além de conhecer um princípio legal ou algum documento que lhe conferiria liberdade, o escravo devia ter certa expectativa de que sua argumentação seria aceita no tribunal, levando-o a crer que a possibilidade de ter um resultado positivo na demanda judicial era maior que os riscos daí advindos. Essa esperança ou convicção poderia advir do conhecimento de demandas semelhantes que tenham resultado em liberdade.

A publicidade que as ações dos escravos nos foros foram ganhando ao longo do século XIX nas senzalas e nas ruas pode ter sido um fator motivador para o aumento progressivo dos processos de liberdade. Além disso, Azevedo (2003: 116) apontou para "o entendimento que os próprios cativos estavam forjando sobre seus direitos, baseados na relação que estabeleciam, não necessariamente com os homens letrados, mas com seus pares". Podemos considerar que esses aspectos se intensificavam quando vividos na Corte, onde o meio urbano e a grande quantidade de negros habitando a cidade facilitavam a comunicação, a mobilidade e a difusão dessas informações.

Nesse sentido, supomos que os aliados que os escravos constituíam na própria experiência da escravidão - livres, forros e outros cativos -, abolicionistas ou não, poderiam ler notícias importantes nos jornais para eles, ou os informar a respeito de disposições legais, promessas, documentos que poderiam thes garantir liberdade. 
Não é possível afirmar com exatidão se os escravos de fato conheciam os códigos e disposições legais que eram citados em seus libelos de liberdade ou que seus curadores arrolavam em sua defesa. Nem se compreendiam os significados jurídicos de suas pendengas contra os senhores. Mas, certamente, estavam a par de elementos e situações que poderiam ser aceitos como plausíveis para justificar sua liberdade diante do aparato judicial, o que aprenderam em sua própria experiência de cativeiro.

A parda Vitória, por exemplo, contou em seu depoimento que "logo que aqui chegou soube que os escravos que vão à Europa ficavam livres"12. Fica difícil saber se ela está se referindo ao seu retorno ao Brasil, em 1843, ou à sua venda à Corte, em 1845. Mas, a julgar pelas suas alegações seguintes e a forma como a história parece se desenrolar, é possível supor que ela tenha tido conhecimento desse direito ao chegar à Corte. Nossa suposição advém da grande quantidade de ações de liberdade que tiveram lugar nessa cidade no século XIX, tendo uma porcentagem alta de sentenças favoráveis à liberdade. É até mesmo provável que escravos de outras localidades procurassem a Corte do Rio de Janeiro para iniciarem processos semelhantes. Essa efervescência jurídica da cidade pode sugerir que houvesse, por extensão, uma grande difusão de informações relativas às disposições legais envolvendo o elemento servil.

Como vimos, Vitória aguardou pacientemente por muitos anos até que tivesse uma oportunidade de reclamar sua liberdade. Todavia, a leitura atenta de seu depoimento no processo mostranos que também outro detalhe foi crucial para motivar sua ida à justiça, apesar dos riscos, naquele momento específico. Além de ter sido vendida para o réu Manoel Simões há poucos meses, Vitória sofrera a ameaça de uma nova venda, uma vez que Simões era negociante na Corte e estava planejando seu envio para a província de Minas Gerais.

A importância desse fato para a decisão de Vitória de "tirar da gaveta" a tal história de viagem à França foi categoricamente

${ }^{12}$ Depoimento em audiência pública da parda Vitória. Idem, f. 36-7. 
afirmada por ela em juízo: "[Manoel Simões] tenciona vende-la para Minas, motivo este, que a fez vir apresentar-se a esta Repartição"13.

Chalhoub (1990: 111-2) já havia ressaltado as tensões em torno das situações de compra e venda dos escravos, que amedrontavam os cativos com um futuro incerto, e incluíam a ameaça de separação de familiares e amigos, venda para lugares indesejados, como as fazendas cafeeiras, e perda de direitos conquistados ao antigo senhor. O mesmo autor observou ainda que situação semelhante de instabilidade era vivida pelos cativos no momento de morte do senhor, já que poderia representar uma possibilidade de alforria em testamento, mas também se configurava como um futuro incerto nas mãos dos herdeiros.

Essas observações se comprovam pela quantidade de processos que foram iniciados nos momentos que envolviam a venda do escravo ou a morte do senhor. Entre as que tiveram lugar na Corte, nada menos que 30 ações de liberdade foram iniciadas em períodos próximos dessas situações, o que corresponde a $77 \%$ do total ${ }^{14}$. Essa recorrência leva a crer que a venda, ou ameaça de venda e a morte do senhor eram momentos decisivos na vida do escravo e que eram também determinantes para motivar a atuação escrava na luta pela liberdade nos tribunais.

Até 1850, o abastecimento de mão-de-obra escrava no Brasil era feito através do comércio de pessoas trazidas da África, em especial de localidades da região Centro-africana. Com a extinção definitiva do tráfico de africanos para o Brasil com a "Lei Eusébio de Queirós", em 1850, os negociantes de escravos se voltaram para o comércio entre as cidades e regiões do Império, sobretudo para responder à demanda por mão de obra das províncias cafeeiras do Sudeste. Por isso, vê-se um significativo aumento da intensidade

\footnotetext{
${ }^{13}$ Declarações que fez a parda Victória na Secretaria de Polícia da Corte, em 20/08/1857. Idem, f. 113v.

${ }^{14}$ Em um montante de 39 ações de liberdade, contabilizamos dezesseis processos iniciados logo após a venda do cativo, oito quando a venda do escravo estava sendo tratada ou o escravo sofrera ameaça de ser vendido, e seis processos iniciados pouco depois da morte do senhor.
} 
do tráfico interno de cativos entre 1850 e 1881, e, principalmente, no último decênio desse período. Desse modo, escravos que nunca haviam passado pela experiência do tráfico, isto é, nascidos no Brasil, e mesmo aqueles que foram trazidos da África para estas paragens, viram aumentar cada vez mais a possibilidade de serem vendidos para o café ao longo da segunda metade do século, o que exige dos historiadores um olhar atento para o impacto do incremento do comércio interno na vida desses indivíduos.

Nesse sentido, Graham (2002: 122) defende que a dolorosa experiência do tráfico interno contribuiu sobremaneira para o aumento da resistência escrava e a progressiva perda da autoridade senhorial sobre esses mesmos cativos. Pena (2006) analisou de modo semelhante o crescimento das revoltas escravas nesse período, concluindo que esses indivíduos "tenderam a resistir ao comércio interno sobre sua vida e seu corpo" (p. 190).

O processo de liberdade de Vitória deixa evidente alguns fatores que podem explicar seu temor à venda para a província mineira. Em primeiro lugar, soubemos pela escritura de compra e venda da parda, anexa ao processo, que ela foi comprada por Manoel Simões junto com seu filho, de apenas três meses de idade. Como não é mencionado se a criança seria vendida junto com a mãe para Minas Gerais, podemos aventar que a tentativa de aquisição da alforria tenha se tornado mais urgente pelo medo da separação do filho ${ }^{15}$.

Além disso, a venda para a província mineira poderia significar o rompimento de outras importantes relações que Vitória tinha na Corte, como as que são possíveis vislumbrar pelo depoimento das testemunhas, que dizem conhecê-la de longa data. Por mais que o mundo dos livres e o dos escravos estivesse em constante contato e o questionamento da escravidão fosse cada vez mais comum nesse período, não era fácil construir um laço

\footnotetext{
${ }^{15}$ Apenas 12 anos após o início do processo de Vitória uma disposição legal foi promulgada para impedir a separação de casais ou de pais e filhos nas transações de venda de escravos, qual seja o Decreto no 1.695 , de 1869, confirmado pela lei 2.040, de 28 de setembro de 1871 .
} 
| 180 |

Escravos nos tribunais...

de solidariedade que sustentasse uma disputa aberta contra um escravocrata nos tribunais. Desse modo, em Minas Gerais, Vitória teria que recomeçar do zero a construção de novas relações que pudessem auxiliá-la em sua luta pela liberdade.

Ao fim do processo judicial, os juízes da primeira e da segunda instância consideraram a ação da parda não provada. Como o passaporte de Benvinda, que teria sido usado por Vitória na viagem à França, descrevia uma idade muito diferente da que ela tinha na época, não era verossímil que tivesse sido aceito pelas autoridades brasileiras ou francesas. Assim, Vitória não conseguiu adquirir sua alforria no tribunal e foi devolvida ao réu Manoel Simões.

É bastante provável que o negociante Simões tenha então efetivado a venda da parda Vitória a Minas Gerais. Até quando ela continuou escrava, ou se tentou mais uma vez intentar uma ação de liberdade ou conseguir sua alforria de outra forma, só seria possível saber com uma extensa busca em documentação judicial e cartorial da Corte e dos municípios mineiros.

\section{Considerações finais}

A história de Vitória elucida as dificuldades e tensões enfrentadas pelos cativos na busca de sua liberdade, e como encontravam saídas para lutar contra um cativeiro ilegal e para influenciar nos rumos de sua própria vida para além do arbítrio do senhor.

Sabemos que, diante do enorme volume da escravaria brasileira no século XIX, o número de cativos que iniciaram processos de liberdade é ínfimo. No entanto, não é insignificante, pois esse pequeno número representa sujeitos que enfrentaram a escravidão de dentro e incentivaram outros a repetir o feito. Não é por acaso que, entre 1850 e 1871, as ações de liberdade da Corte de Apelação triplicaram com relação às décadas anteriores e que tenha havido um aumento progressivo da participação de escravos rurais nesses processos, como aponta Castro (1997: 355). 
Essa movimentação cativa em torno dos tribunais caminhou na mesma mão do crescimento acelerado do tráfico interno em direção às fazendas cafeicultoras do Sudeste e da progressiva perda de legitimidade do sistema escravista no bojo dos discursos abolicionistas e da resistência dos próprios cativos contra a [re] escravização ilegal e os abusos dos senhores.

Esses homens e mulheres escravizados tiveram que lidar com documentos complexos que citavam apenas superficialmente seus direitos, com promessas orais de liberdade que eram negadas, com dívidas cobradas aos falecidos senhores que resultavam no prejuízo de suas alforrias, e muitas outras situações em que apenas sua interpretação insistente em defesa da própria liberdade poderia lhes dar alguma sustentação nos foros. Desse modo, forçaram ao máximo a interpretação da lei e o sentido de costumes que, mesmo não inscritos nos códigos legais, poderiam garantir-lhes o direito à alforria.

Por outro lado, não podemos inferir que esses escravos estavam sempre "falando a verdade", ou que todas as razões apresentadas para a liberdade nesses documentos partiam de fatos verdadeiros da forma como foram alegados em juízo; essa seria uma análise ingênua. Porém, é possível supor que algumas histórias fossem inventadas com uma percepção de que poderiam ser levadas em conta dentro de uma situação ou de um clima jurídico que fosse favorável. Ou seja, dentro de um campo de possibilidades percebidas por esses sujeitos como momentos-chave em que a liberdade poderia ser conseguida. O recurso à justiça deve, portanto, ser entendido como fruto de certa sofisticação na análise da conjuntura em que seriam julgadas, mesclada à racionalidade própria dos escravos.

Por racionalidades próprias entendemos os diversos valores, expectativas e tensões compartilhadas pelos indivíduos em cativeiro ${ }^{16}$. Castro (1997: 359-360) observou que, pelo menos desde a extinção do tráfico africano de escravos em 1850, essas expectativas se configuraram no cotidiano da relação com o

${ }^{16}$ Emprestamos a expressão de Chalhoub, 1990: 252. 
senhor na forma de direitos, que implicaram na generalização do sentido de expressões como "cativeiro justo" e "bom senhor", e na resistência ao oposto "mau cativeiro", "mau senhor", que não mereceria obediência. A presença recorrente dessas expressões nos processos que analisamos neste estudo mostra, portanto, um esforço dos cativos de conferir à lógica da sociedade escravista seus próprios significados, manipulando-a contra a própria escravidão.

Dessa forma, é importante ressaltar que a mobilização dos escravos contra o cativeiro não acontecia apenas como uma reação instintiva a momentos de tensão e incerteza relacionados ao tráfico interno, apesar da relevância que, de fato, tinham os momentos de compra e venda. $\mathrm{O}$ recurso à justiça ocorria, em especial, diante do que os cativos entendiam como desrespeito a determinados direitos, e provinha de um cálculo entre os riscos e possibilidades. Nos processos envolvendo a partilha dos bens de um senhor falecido ou a venda para locais distantes, percebemos a intenção dos cativos de ter respeitado o direito de não separação da família ou de participar nas transações que decidiriam seu futuro, não sendo transferidos para lugares indesejados, por exemplo.

A análise desses processos reforça ainda a conclusão de que o escravo vivia uma "resistência permanente a ser um mero objeto nas malhas do sistema" (REIS e SILVA, 1989: 07), reagindo contra tentativas de reescravização e contra o desrespeito a direitos conquistados pelo costume.

Se o recurso aos tribunais não foi utilizado pela maioria dos escravos do Oitocentos, devemos pelo menos considerar sua importância como possibilidade. Isso faz desses cativos partícipes de uma história real e dinâmica, e não ideal, ou seja, cercada por obstáculos e alternativas, que não se apresentaram de igual modo a todos, nem em todos os momentos, mas que permitiam certa manipulação e mobilidade. Assim, a liberdade e demais prerrogativas da vida do cativo não estavam determinadas apenas pela vontade do senhor, mas sim pela capacidade do indivíduo escravizado de se movimentar dentro dessas possibilidades e espaços. 


\section{Referências}

\section{Fontes primárias manuscritas:}

Arquivo Edgard Leuhenroth (AEL - IFCH - UNICAMP): Fundo Relação do Rio de Janeiro - Apelações Cíveis, Rio de Janeiro (1812-1878).

\section{Referências bibliográficas:}

AZEVEDO, E. Orfeu de Carapinha: a trajetória de Luiz Gama na imperial cidade de São Paulo. Campinas: Editora da UNICAMP, 1999.

AZEVEDO, E. Direito dos escravos: lutas jurídicas e abolicionismo na província de São Paulo na segunda metade do século XIX. Tese (Doutorado) - Campinas: Unicamp, 2003.

CASTRO, H. M. M. de. Laços de família e direitos no final da escravidão. In: NOVAIS, F. (coord.). História da vida privada no Brasil: Império. São Paulo: Companhia das Letras, 1997, p. 337-383.

CHALHOUB, S. Visões da liberdade: uma história das últimas décadas da escravidão na corte. São Paulo: Companhia das letras, 1990.

FREITAS, L. G. B. Escravos nos tribunais: o recurso à legislação emancipacionista em ações de liberdade do século XIX. Monografia - Campinas: Unicamp, 2012.

GRAHAM, R. Nos Tumbeiros Mais Uma Vez? O Comércio Interprovincial De Escravos No Brasil, Afro-Ásia, 27, Salvador, UFBA, 2002, p. 121-160.

GRINBERG, K. Escravidão e relações diplomáticas Brasil e Uruguai, século XIX. IV Encontro Escravidão e Liberdade no Brasil Meridional, Curitiba, 2009. 
GRINBERG, K. Liberata: a lei da ambiguidade: as ações de liberdade da corte de apelação do Rio de Janeiro no século XIX. Rio de Janeiro: Relume-Dumará, 1994.

MAMIGONIAN, B. G. e GRINBERG, K. (org.) Dossiê "Para inglês ver"? Revisitando a Lei de 1831. Estudos Afro-Asiáticos, Rio de Janeiro, ano 29, nºs 1/2/3, jan-dez 2007.

MENDONÇA, J. M. N. [1999] Entre a mão e os anéis: a lei dos Sexagenários e os caminhos da abolição no Brasil. 2 ed. Campinas: Editora da UNICAMP, 2008.

PENA, E. S. Burlas à lei e revolta escrava no tráfico interno do Brasil meridional, século XIX. In: LARA, S. H. e MENDONÇA, J. M. N. (org.). Direitos e justiças no Brasil: Ensaios de história social. Campinas: Editora da Unicamp, 2006, p. 161-197.

PENA, E. S. Pajens da Casa Imperial: jurisconsultos, escravidão e a lei de 1871. Campinas: Editora da UNICAMP, 2001.

REIS, J. J. e SILVA, E. Negociação e conflito: a resistência negra no Brasil escravista. São Paulo: Companhia das Letras, 1989. 